\title{
USO DAS TIC E PROJETOS TEMÁTICOS: NOVAS PERSPECTIVAS PARA PLANEJAMENTO E EXECUÇÃO DE ATIVIDADES ESCOLARES
}

\author{
Rita de Cássia Bortoletto-Santos, Neucideia Aparecida Silva Colnago, \\ Yvonne Primerano Mascarenhas
}

Instituto de Estudos Avançados

Universidade de São Paulo

São Carlos, São Paulo

E-mail: ritabortolettosantos@gmail.com,nacolnago@gmail.com,yvonne@ifsc.usp.br

Resumo: A educação atual fundamenta-se na construção de conhecimento e no desenvolvimento de competências. Diante disso, professores de escolas públicas na cidade de São Carlos/São Paulo (Brasil), planejaram e executaram atividades com o uso das TIC e temas geradores. Verificar como esses professores percebem o uso das TIC no processo de ensino-aprendizagem foi o objetivo de investigação de abordagem qualitativa, utilizando questionários e análise de conteúdo. Como resultado se chegou a três temas: Direcionamento do uso das TIC, Dificuldades de uso das TIC e Contribuições do uso das TIC no processo de ensino e de aprendizagem. Concluiu-se que embora o professor tenha algumas dificuldades em incluir as TIC de forma apropriada e contextualizada, essas ferramentas motivam os estudantes para a aprendizagem.

Palavras-chave: TIC, contexto escolar, temas geradores, ensino-aprendizagem.

USE OF ICT AND THEMATIC PROJECTS: NEW PERSPECTIVE FOR PLANNING AND IMPLEMENTATION OF SCHOOL ACTIVITIES

\begin{abstract}
The current education system is based on the construction of knowledge and development of skills. Given this, teachers of public schools in the city of São Carlos/São Paulo (Brazil), planned and executed activities with the use of ICT and generator themes. See how these teachers perceive the use of ICT in the teaching-learning process has been the goal of qualitative research, using questionnaires and content analysis. As result three themes were achieved: Targeting the use of ICT, Difficulties in using the ICT and Contributions of the use of ICT in the teaching and learning process. It was noticed that, although the teacher has some difficulties to include ICT appropriately and contextualized, these tools motivates the student's learning.
\end{abstract}

Keywords: ICT in the school context. generating themes. learning education.

Recebido em 30/09/2015. Publicado em 30/03/2016. 


\section{INTRODUÇÃO}

Na sociedade da informação os conhecimentos circulam rapidamente e a educação nessa sociedade fundamenta-se na construção do conhecimento e no desenvolvimento de competências, relacionadas a aprender a buscar informações, compreendê-las e saber utilizá-las na resolução de problemas. Para isso há a necessidade de se reaprender a conhecer, a comunicarse, a ensinar e a aprender. Esse desafio passa não só pela formação dos indivíduos que as escolas devem formar, mas também pela atuação dos professores no contexto escolar, que devem perceber a necessidade de inserir novas metodologias e recursos no cotidiano da sala de aula.

Estudos mostram que a estratégia de utilizar a tecnologia da informação e da comunicação (TIC) nas atividades já existentes na escola e nas salas de aula, sem alterar as práticas habituais de ensino não produz melhores resultados na aprendizagem dos alunos (DE CORTE, 1993; JONASSEN, 2007; WILSEK e TOSIN, 2009). A utilização das novas tecnologias como estratégia no planejamento e execução de atividades escolares requer do professor uma nova percepção de seu papel mediador e orientador diante de múltiplas possibilidades para o estudante alcançar o conhecimento (KENSKI, 1999).

A reformulação do trabalho realizado nas escolas, referente ao processo de ensino-aprendizagem, permite o trabalho contextualizado e próximo da realidade dos alunos e dos professores. Nesse contexto o professor deve assumir a posição de orientador do processo de ensino-aprendizagem, estimulando a curiosidade de seus alunos pela Natureza, Ciência, Tecnologia, além da realidade local e universal, que é veiculada através dos meios de comunicação, levando para as salas de aulas discussões que possam realmente ter significado para seus alunos, usufruindo de sua autonomia e liberdade para tomar decisão ao planejar e executar atividades com seus alunos (FREIRE,2000).

Com base nessas ideias, desde 2009 algumas escolas da rede estadual da cidade de São Carlos (São Paulo/Brasil) têm desenvolvido, em parceria com o Instituto de Estudos Avançados da Universidade de São Paulo (IEA/USP-Polo São Carlos), projetos de trabalho, envolvendo a utilização das TIC (Tecnologias da Comunicação e Informação) no contexto escolar, possibilitando a orientação e utilização de ferramentas computacionais associadas à concepção de temas geradores. 
Dos objetivos dessas atividades destacam-se a mobilização dos estudantes pelos conteúdos disciplinares e o desenvolvimento de habilidades relacionadas à competência leitora e escrita e à busca de informações utilizando a Internet, inserção das TIC nas aulas de um modo criativo e participativo, que culminasse na elaboração de um registro final do trabalho inovador realizado pelos estudantes com formato digital utilizando diferentes ferramentas multimídia.

Diante desse contexto surgiu a questão que motivou esta investigação: como os professores envolvidos em projetos temáticos, nos anos finais do ensino fundamental, percebem o uso das mídias e tecnologias digitais no processo de ensino e de aprendizagem? Definindo-se como objetivo verificar como professores envolvidos em projetos temáticos, nos anos finais do ensino fundamental, percebem o uso das mídias e tecnologias digitais no processo de ensino e de aprendizagem.

A ideia de tema gerador proposta por Paulo Freire em sua obra discorda da fragmentação e da necessidade de conteúdos serem trabalhados de forma isolada. Embora os projetos de trabalho que deram origem às experiências vividas pelos professores, envolvendo as TIC no contexto escolar, não tenham partido de questionamentos originados pelos alunos, adota-se a perspectiva de tema gerador como referencial teórico, entendendo tratar-se de uma maneira de organizar os conteúdos buscando a problematização. Esses temas, que abordaram questões referentes à Astronomia, água, sustentabilidade e microrganismos, faz com que o eixo temático assuma o papel de fio condutor para articular conhecimentos.

Aprofundando essas ideias, é preciso deixar de lado o papel do professor como sujeito e do aluno como objeto no processo educacional. Educar não é somente transferência de conhecimento, deve haver construção de conhecimento de ambos os lados. "Quem ensina aprende ao ensinar e quem aprende, ensina ao aprender" (FREIRE, 2000, p.25). Assim, os professores ao planejarem e executarem atividades utilizando temas geradores optaram por contextualizar os conteúdos e reorganizar sua prática docente, utilizando para isso as TIC, no que se refere ao levantamento de informações ou elaboração de registros finais (no formato de blog ou CD ROM).

Paulo Freire nos mostra que a simples transferência de informação como "depósitos bancários" não gera conhecimento naqueles que a recebem. Trata-se de uma educação inibidora, a qual pretende levar o homem a ajustar-se ao mundo, impedindo que atue como sujeito criativo (FREIRE, 1981). Em contraposição a essa educação bancária o professor dever criar condições que 
estimulem o aluno a construir conhecimento. A curiosidade é algo próprio do se humano, mas que muitas vezes é reprimida pela sociedade. É preciso estimular a pergunta e a reflexão.

O professor, como orientador no processo de aprendizagem, sinaliza com novos caminhos para que seus alunos elaborem uma nova leitura do fato e construam seu conhecimento (FREIRE,1994; PARDO, 1997). Nesta perspectiva o planejamento e execução de atividades com temas geradores e uso das TIC pode ser um referencial inovador, contemporâneo e motivador a ser adotado.

Quando dizemos que o processo educativo é coletivo, devemos pontuar também o aprendizado do professor que cria estratégias pedagógicas, as quais permitem aos alunos expressarem seus pensamentos e perguntas, deixando de lado a proposta de aulas já prontas, nas quais os alunos devem anotar e prestar atenção às explicações dadas pelo professor, não sendo permitido aos alunos construírem seu próprio conhecimento. Nossas respostas começam a ser construídas quando nos entendemos como seres comprometidos com nosso tempo, inseridos no contexto que ajudamos a construir e sendo capazes de observá-lo, objetivá-lo, utilizando nossa capacidade de agir e refletir. Uma educação tão ampla quanto a vida, com significado e utilização. Nessa perspectiva, a inclusão de novas tecnologias no contexto escolar favorece um processo educacional mais atualizado e motivador.

Vale salientar que os avanços das TIC e seu processo de transformações sociais e culturais, merecem destaque aquelas relacionadas ao uso do computador. Esse aparelho já faz parte de nosso cotidiano trazendo "novas maneiras de viver, trabalhar, se organizar, representar a realidade e fazer educação" (KENSKI, 1999). Ao chegar, de modo mais significativo, às escolas brasileiras no final dos anos de 1990, o uso do computador sinalizava "novos modos de aprender e ensinar" tanto para alunos como para professores (GOMES, 2002). Nesse contexto professor e aluno, tornam-se protagonistas de uma história escrita na velocidade de nosso tempo. Na sociedade da informação todos estamos reaprendendo a conhecer, a comunicar-nos, a ensinar e a aprender; a integrar o humano e o tecnológico; a integrar o individual, o grupal e o social (MORAN, 2000).

Os conceitos globalização e velocidade sintetizam nosso mundo e convidam a escola, a repensar seu papel no que diz respeito aos estudantes acessarem informações, interagirem com elas e superá-las pelo novo (KENSKI, 1999). A educação deve ser baseada na construção do 
conhecimento e no desenvolvimento de competências, relacionadas a aprender a buscar informações, compreendê-las e saber utilizá-las na resolução de problemas.

A introdução do computador nas atividades realizadas na escola foi e é uma tentativa de modernizar ou repensar a educação. Algo que exige do professor uma formação mais ampla, envolvendo os vários recursos que apresenta e que podem auxiliar no processo de transformação da escola, criando ambientes de aprendizagem com ênfase na construção do conhecimento e não somente na instrução (VALENTE, 1995), como ocorre em modelos educacionais tradicionais.

Segundo Perrenoud (2000) o computador não é um instrumento próprio da escola, porém não pode ficar fora dela. Estudantes consultando a Internet, ou utilizando diferentes ferramentas para suas produções devem ser estratégias incorporadas à prática docente, cabendo ao professor relacioná-las aos objetivos e conteúdos de ensino, ampliando o espaço da sala de aula.

No entanto, a formação dos professores relativos ao uso das TIC é exígua ou não atende às necessidades para as utilizarem no contexto educacional além de que o ambiente de trabalho não oferece infraestrutura adequada. A aplicação das novas tecnologias como estratégia didática requer do professor uma nova percepção, não se posicionando mais como o "dono do saber", mas sim, como parceiro que encaminha e orienta o estudante diante de múltiplas possibilidades de alcançar o conhecimento (KENSKI, 1999), especialmente, se considerarmos que para muitos estudantes, a escola é vista como único acesso ao conhecimento construído pela Humanidade, possibilitando-Ihes o contato com novos recursos tecnológicos e a apropriação do conhecimento elaborado. Aos professores cabe apropriar-se das TIC com um olhar critico e responsável, vendose como agentes transformadores da realidade, que devem desenvolver competências para incluir em sua prática docente.

As novas tecnologias permitem criar situações de aprendizagem mais ricas, complexas, numa dimensão interativa, que não se caracterize somente em "dar aulas melhores", mas que possibilitem aos alunos realmente aprenderem. A escola segundo Tardif (2002) está centralizada na aprendizagem e não mais no ensino, dessa forma "o oficio do professor redefine-se: mais do que ensinar, trata-se de fazer aprender". Não é simplesmente, trocar a ideia da educação bancária, criticada por Paulo Freire, por um "caixa automático", no caso o computador, que 
guarda em seu poder a possibilidade de diminuir distâncias geográficas e temporais, acelerando o conhecimento de informações no mundo.

As atividades devem ir mais além, explorando a criatividade e novas habilidades, possibilitando que a democratização digital diminua também distanciamentos sociais (MORAN, 1997), porque muitos dos jovens que passam pela escola pública, não têm oportunidade de contato com orientações e uso de computadores e suas possibilidades são menores ainda em espaços fora da escola.

\section{PERCURSO METODOLÓGICO}

Com objetivo de responder às questões deste trabalho, optou-se por uma pesquisa de abordagem qualitativa, considerando que valoriza o instrumento humano (ALVES, 1991; LUDKE \& ANDRÉ, 1986), no caso, as ideias dos professores. A abordagem qualitativa permite ampliar a compreensão de fenômenos educacionais, de modo complexo e contextualizado, além de permitir ao professor vir à cena, através de suas concepções e expectativas (GHEDIN \& FRANCO, 2008).

Com base nas ideias acima, utilizou-se como instrumento de coleta dados um questionário, com cinco questões abertas, de formulação e ordem uniformizadas, mas sem opção de resposta previamente determinada (LAVILLE e DIONNE, 1999). O questionário foi enviado por e-mail para sete professores, escolhidos como grupo de sujeitos por terem participado do planejamento e execução de atividades escolares, que utilizaram um tema gerador (astronomia, sustentabilidade, água, microrganismos) e as TIC, desenvolvidos no período de 2009-2014 em escolas estaduais da cidade de São Carlos. Deste grupo, somente cinco professores devolveram o questionário respondido.

Inicialmente, procurou-se caracterizar os participantes, quanto à idade, sexo, tempo de magistério, disciplinas, anos que leciona, e se haviam realizado algum curso referente ao uso das TIC. As questões apresentadas aos sujeitos foram construídas com o objetivo de verificar a utilização de eixos temáticos e TIC no planejamento e execução de atividades escolares e sua percepção quanto ao uso delas no processo de ensino e de aprendizagem. Os dados foram explorados através da análise de conteúdo, buscando extrair a significação das palavras (LAVILLE e DIONNE, 1999). Trata-se de um conjunto de técnicas de análise das comunicações (BARDIN, 2008) que têm como ponto de partida a mensagem (no caso escrita) que expressa um significado. 
No caso desta pesquisa, buscou-se analisar nos comentários dos professores, a sua percepção quanto ao uso das TIC em atividades planejadas e executadas, nos anos finais do ensino fundamental e sua colaboração no processo de ensino e de aprendizagem. Destaca-se a opção de análise por temas, a partir das informações contidas nos comentários dos professores entrevistados (BARDIN, 2008). Os temas foram definidos a posteriori, emergindo a partir de várias leituras dos questionários, sem uma hipótese pré-estabelecida. A partir de novas organizações dos temas surgiram as categorias apontadas nos resultados. Por uma questão de organização e para facilitar a apresentação dos dados, optou-se em de nomear os sujeitos pela sigla P (professor), seguidos por números, de modo aleatório, sem uma ordem pré-determinada.

\section{RESULTADOS E DISCUSSÃO}

\subsection{Caracterização dos sujeitos}

Justificando a opção metodológica pela abordagem qualitativa, o Quadro 1 apresenta a caracterização dos sujeitos, quanto à idade, sexo, experiência no magistério (tempo e disciplinas que leciona) e a realização de cursos referentes ao uso das TIC em atividades escolares. Optou-se por identificá-los com a letra "P” (professor) seguido de um número: P1, P2, P3, P4 e P5.

Quadro 1. Caracterização dos Sujeitos.

\begin{tabular}{|c|c|c|c|c|c|c|}
\hline 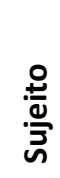 & $\begin{array}{l}\frac{0}{0} \\
\frac{\pi}{0}\end{array}$ & $\stackrel{\circ}{\stackrel{x}{\sharp}}$ & 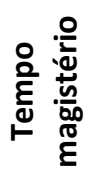 & Disciplina & Anos & Você fez cursos referentes ao uso das TIC? \\
\hline$P_{1}$ & 39 & $\mathrm{~F}$ & 18 & $\begin{array}{l}\text { Português } \\
\text { Inglês }\end{array}$ & 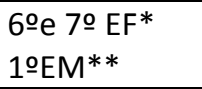 & Sim, Proinfo (Governo Federal) \\
\hline $\mathrm{P}_{2}$ & 53 & $\mathrm{~F}$ & 28 & Ciências & 6으 ао 9 $\mathrm{EF}$ & $\begin{array}{l}\text { Sim, Workshops sobre Microsoft PowerPoint e } \\
\text { Microsoft Movie Maker (na escola privada e } \\
\text { Parceira - IEA/escola estadual), Formação de } \\
\text { tutores e Currículo+ (SEESP) }\end{array}$ \\
\hline$P_{3}$ & 52 & $\mathrm{~F}$ & 29 & $\begin{array}{l}\text { Educação } \\
\text { Física }\end{array}$ & $\begin{array}{l}\text { 60 e 70 EF } \\
\text { 2o EM }\end{array}$ & Sim, Currículo + (SEESP) \\
\hline $\mathrm{P}_{4}$ & 40 & $\mathrm{~F}$ & 17 & Ciências & $\begin{array}{l}\text { 6o, 70 e 8o } \\
E F\end{array}$ & Não \\
\hline$P_{5}$ & 63 & M & 27 & História & $\begin{array}{l}\text { 50 e 6o EF } \\
\text { 3o EM }\end{array}$ & $\begin{array}{l}\text { Sim, Educomunicação (parceria UFSCar/escola } \\
\text { pública), Workshop (parceria IEA/ escola) e cursos } \\
\text { da SEESP. }\end{array}$ \\
\hline
\end{tabular}

Fonte: Dados da pesquisa. ${ }^{*} \mathrm{EF}=$ Ensino Fundamental **EM= Ensino Médio

*** SEESP = Secretaria de Educação do Estado de São Paulo. 
Dos cinco professores participantes, apenas um é do sexo masculino. Fato comprovado em levantamentos recentes sobre o perfil dos professores da educação básica brasileira, que indicam que apesar do crescimento da participação masculina, a profissão docente ainda é majoritariamente feminina: em 2013 era composta por 83,1\% de mulheres (DIEESE, 2014). A idade dos professores variava de 39 a 63 anos (média de 49,4 anos), o que pode ser explicado pelo aumento de tempo do professor na carreira, em 2002 tínhamos 673 mil professores com mais de 40 anos nas salas de aula (34,9\%), em 2013 havia 1,1milhão na mesma faixa etária $(46,1 \%)$.

Seguindo essa linha de pensamento percebemos que o tempo de atuação no magistério (no grupo de sujeitos) variou de 17 a 29 anos, correspondendo a media de 23,8 anos, aspecto que nos leva a inferir tratar-se de professores experientes, utilizando-se a concepção de Tardif (2000), considerando que já possuem elementos que fundamentam sua atuação pela experiência do próprio trabalho. Há uma diversidade nas disciplinas lecionadas pelos sujeitos: Português e Inglês, Ciências (2), Educação Física e História. Todos atuam nos anos do ensino fundamental e três atuam também no ensino médio. Fato que nos permite inferir que área de formação não restringe a possibilidade de planejar e executar atividades envolvendo a utilização das TIC no contexto escolar (considerando que um critério na escolha dos sujeitos era sua participação nos projetos descritos acima).

Dos cinco professores participantes somente um não fez nenhum curso sobre as TIC. Quanto aos demais, percebe-se a importância da parceria entre as universidades e as escolas públicas para a realização de cursos voltados ao uso das TIC no contexto escolar ( 2 professores) e o oferecimento de cursos de curta duração, na modalidade à distância oferecidos por entidades governamentais (como MEC e SEESP) contribuindo para a atualização e formação continuada dos professores.

A formação técnica oferecida aos docentes para que eles possam lidar com as ferramentas tecnológicas exige reconstruir e transformar o processo de ensino e de aprendizagem em algo dinâmico. Segundo Kenski (2008) o uso de tecnologias tem o efeito de criar mudanças em relação à cultura da sociedade, incluindo-se a própria cultura educacional. Talvez esteja aqui um dado relevante, a necessidade de aproximação entre as universidades e as escolas de educação básica e a atuação de órgãos públicos ligados à administração escolar (diretorias e secretarias de ensino) 
no oferecimento de cursos de atualização e troca de experiências quanto ao uso das TIC nas atividades escolares.

\subsection{Percepção dos professores quanto ao uso das TIC}

Após a análise do conteúdo disponível no questionário, emergiram três temas, dos quais se chegou a três categorias, conforme o Quadro 2, que serão discutidas abaixo:

Quadro 2. Categorias.

\begin{tabular}{|l|l|}
\hline \multicolumn{1}{|c|}{ Tema } & \multicolumn{1}{|c|}{ Categorias } \\
\hline 1) Direcionamento do uso das TIC & - Levantamento de informações \\
& $\begin{array}{l}\text { - Apresentação de vídeos } \\
\text { - Elaboração de materiais }\end{array}$ \\
\hline 2) Dificuldades de uso das TIC & - Aspectos físicos \\
\hline 3) Contribuições das TIC & - Aspectos humanos \\
& - Processo de ensino \\
\hline
\end{tabular}

Fonte: Dados da pesquisa.

\subsection{Direcionamento do Uso}

Ao analisar as questões:

1) você já utilizou mídias e tecnologias digitais em suas aulas? Em caso afirmativo, descreva em que situação?

2) quais os recursos o professor e/ou seus alunos utilizam na elaboração de atividades de aula? Surgiram aspectos nos comentários dos sujeitos, que permitem organizar as respostas no primeiro tema - Direcionamento do uso - apontando para três categorias: levantamento de informações, apresentação de vídeos e elaboração de materiais.

A primeira refere-se ao levantamento de informações, por parte dos alunos, na Internet e a segunda refere-se à apresentação de vídeos como sugerem os comentários de:

P3: "Utilizei a internet como ferramenta para pesquisas e vídeos para ilustrar os conteúdos".

P2: "[...] utilização de vídeos para ilustrar temas referentes à disciplina de Ciências (ex. água, sistema solar); [...] levantamento de informação na Internet sobre determinados temas".

P4: "Sempre uso em pesquisas direcionadas e vídeos". 
Esses dados confirmam o papel que as TIC assumem nos dias atuais, no que se refere à rapidez com que as informações circulam no novo modelo de sociedade globalizada. Em termos de comunicação, sintetiza nosso mundo e convidam a escola, a repensar seu papel no que diz respeito aos estudantes acessarem informações, interagirem com elas e superá-las pelo novo (KENSKI, 1999).

Quanto à apresentação de vídeos, no ensino das Ciências permitem aos professores aproximar dos contextos das salas de aula experimentos de difícil execução no contexto escolar, pela velocidade que ocorrem (muito rápidos ou muito lentos) dificultando sua percepção pelos alunos, ou a reprodução de algum experimento que põe em risco a segurança dos estudantes. Além desses aspectos, facilita a visão do micro e do macro, ao apresentar os elementos de uma célula ou a dimensão do nosso Sistema Solar. Nas disciplinas de História e Geografia, permitem ao estudante visualizar conteúdos estudados de modo estanque nos livros didáticos, recriando aspectos históricos ou retratando paisagens de modo mais amplo e dinâmico.

A terceira categoria refere-se à elaboração de materiais utilizando as TIC, como sugere o comentário de:

P1: "[...] Com o projeto da USP utilizei o programa Hagaquê (Historias em quadrinho) e na construção do Blog para o final do curso Proinfo".

P5: "Desenvolvemos em parceria com o Curso de Imagem e Som uma série ficcional abordando os temas transversais como saúde, orientação sexual, etc. Temos também um programa de rádio onde praticamos educomunicação".

Os exemplos citados nos comentários dos professores sinalizam para o uso das TIC de modo criativo, explorando o desenvolvimento de diferentes habilidades, entre elas o domínio da comunicação, na forma oral ou escrita, habilidade requerida pelo contexto social atual. Quanto a quais recursos das TIC utilizaram, os cinco professores relataram que fazer uso da internet para pesquisa, três deles para a digitação de textos (Word), três para apresentação e elaboração de aulas usando a ferramenta PowerPoint ${ }^{\circledR}$, um para elaborar um Blog. Três deles também utilizaram espaços virtuais de aprendizagem (espaços de discussões). Chamou a atenção, que neste grupo de sujeitos, nenhum dos professores utilizou a ferramenta Excel, talvez pela própria formação inicial do grupo que não incluiu professores de matemática. 


\subsection{Dificuldades de Uso}

Ao analisar a questão:

3): se a escola facilita (ou não) o acesso e o uso de mídias e tecnologias digitais no planejamento e execução das aulas? Chegou-se ao tema - dificuldade de uso (das TIC), emergindo duas categorias a partir dos aspectos apontados nos comentários dos sujeitos: aspectos físicos e aspectos humanos.

Aspectos físicos: referem-se às condições dos recursos disponíveis na escola, como apontado no comentário de:

P2: "[...] trabalhar com 20 computadores - 40 alunos divididos em duplas, em 2011 e 2012 tivemos problemas com a mudança da sala de informática para um local menor, computadores quebrados e dificuldades quanto ao uso da Internet-conexão e velocidade".

P3 "[...] as maiores dificuldades são nos trabalhos de pesquisas que tem poucos computadores e alguns com defeitos $e$ uma única lousa digital para toda U.E que deve ser agendada com antecedência".

A inserção dos recursos tecnológicos nas escolas, referentes às TIC, deve acontecer de modo adequado, com planejamento e manutenção constante dos computadores e da rede, principalmente no que diz respeito ao número de equipamentos disponíveis ou da velocidade de acesso à Internet. Repor peças danificadas e revisões periódicas pode manter a utilização das TIC no contexto escolar de modo eficiente, favorecendo o planejamento e execução de atividades diferenciadas.

Aspectos humanos: embora haja o apoio da equipe gestora na utilização dos recursos e espaços disponíveis, como assinalado no comentário de:

P5: "[...] dá todo o apoio possível! os professores não se sentem seguros e confortáveis sem terem um monitor ou outra pessoa para auxiliá-los diante de turmas numerosas".

P1: "[...] temo um pouco quando tenho que usar sozinha com uma sala de quarenta alunos. Com a ajuda dos estagiários da USP isso fica mais fácil, principalmente porque este ano restringiram o número de estagiários do Acessa".

A preocupação do professor estende-se ao cuidado com os computadores material da sala de informática, além da preocupação em conduzir as atividades propostas. Esse aspecto aparece no comentário de: 
P4: "[...] quase sempre tem uma dificuldade, agora, por exemplo, não temos monitor na sala de informática, consequentemente dificulta ainda mais o nosso trabalho, pois seremos responsável por todo funcionamento da sala, além da nossa aula dirigida".

Neste ponto, podemos inferir a necessidade de inserir nos cursos de formação de professores (inicial ou continuada) orientações especificas, quanto ao uso, planejamento e execução de atividades que utilizem as TIC. A presença de um monitor ou auxiliar para acompanhar os professores em suas atividades nos laboratórios de informática, pode ser um fator facilitador diante do número de alunos nas salas de aula da escola pública.

\subsection{Contribuições das TIC}

Ao analisar a questão 4 (Como o professor percebeu sua atuação no desenvolvimento de projetos que utilizaram eixos temáticos e as TIC em sua execução? Essa estratégia pedagógica facilitou ou dificultou seu trabalho em sala de aula?) e a questão 5 (Como você percebeu a aprendizagem de seus alunos ao utilizar TIC na execução de das atividades propostas?) chegou-se ao tema contribuições das TIC, emergindo duas categorias: no processo de ensino e no processo de aprendizagem.

Quanto à primeira categoria - contribuição das TIC no processo de ensino, os comentários dos sujeitos apontaram para uma aproximação entre o que será ensinado e a realidade do aluno. Conforme o comentário:

P3: "Percebi que tive autonomia para pesquisar o material adequado à realidade escolar, facilitando no aprendizado dos alunos".

Algo muito próximo do que Freire (2000) sugeria, permitir ao professor ter autonomia para planejar e executar atividades próximas ao cotidiano do aluno, que tivessem significado para ele. Porém, para que haja efetiva contribuição no processo de ensino, as atividades que envolvem o uso das TIC requerem do professor mais atenção quanto ao seu planejamento, como aponta o comentário:

P2: "[...] tive que buscar mais informações e parcerias para poder realizar as atividades propostas, principalmente pelo número de alunos em cada turma (40). Como os trabalhos propostos eram realizados através de eixos temáticos (Astronomia, Sustentabilidade, Ciência, Química no cotidiano) para cada um deles, tive que me aprofundar no assunto, 


\section{Bortoletto-Santos, Colnago e Mascarenhas, 2016 - Tecnologia Educacional}

buscando conhecimento suficiente para propor questões para os alunos, e ser capaz de orientá-los nas atividades desenvolvidas. Para auxiliar na passagem de informações sobre o uso da Internet e da ferramenta PowerPoint ${ }^{\circledR}$, contar com um grupo de bolsistas do IEA/USP foi fator importante para um atendimento mais individualizado e solução de dúvidas quanto à utilização desses recursos. Talvez aqui um ponto não desfavorável, mas mais trabalhoso".

Podemos entender que a seleção das tecnologias educacionais ou a incorporação delas na prática pedagógica é uma ação atrelada aos saberes docentes. Dessa forma, os professores precisam conhecer as tecnologias educacionais para que possam adotá-las de forma efetiva e eficaz, incorporando-a com propriedade à sua práxis. (BORTOLETTO-SANTOS et al., 2014).

Quanto à categoria - contribuição do uso das TIC no processo de aprendizagem destaca a perspectiva deste tipo de trabalho produzir uma aprendizagem mais significativa e prazerosa, aumentando a motivação dos alunos, como sugere os comentários do:

P4: "Facilita muito, pena que muitas vezes esbarramos com outros problemas que dificultam a aplicação. Acredito que as TIC integram o conteúdo com a tecnologia, de maneira que o aluno se interessa mais porque faz parte do mundo dele, isso proporciona uma aprendizagem significativa e prazerosa".

Neste ponto o trabalho com temas geradores associados ao uso das TIC, pode ser uma associação facilitadora para mobilizar os estudantes à aprendizagem, aproximando assuntos contemporâneos, não livrescos dos conteúdos a serem estudados nas diferentes disciplinas. Os comentários foram:

P2: "Os alunos demonstraram maior interesse sobre o que era trabalhado, aumentou a motivação para as aulas, eles puderam por em prática sua criatividade ao elaborar os slides que compuseram o registro digital final do projeto Almanaque Digital".

P3: "Os alunos participaram com mais empenho e motivados durante as atividades".

Os comentários desses professores reforçam a contribuição das TIC no processo de aprendizagem dos alunos, por seu interesse, motivação e participação nas atividades escolares sugeridas. Dos cinco professores, dois deles verificaram que com o uso das TIC aumentou a motivação, a criatividade e a participação dos alunos nas atividades propostas e um deles relatou que o uso de filmes/vídeos contribui para uma visão objetiva da disciplina história. Entretanto, dois deles relataram o desinteresse de alguns alunos, mas reconhecem que o uso das TIC no ambiente escolar quebra a rotina de sala de aula e os alunos ficam mais animados e a outra considera que 


\section{Bortoletto-Santos, Colnago e Mascarenhas, 2016 - Tecnologia Educacional}

seu uso auxilia na aprendizagem, mas a maioria dos alunos apresentam desinteresse. Nessa perspectiva, novas tecnologias permitem criar situações de aprendizagem mais interativas e otimizar a participação do aluno no seu processo de aprendizagem o que não se caracteriza somente em "dar aulas melhores", mas que possibilitem aos alunos realmente aprenderem (BORTOLETTO-SANTOS et al.,2014).

\section{CONSIDERAÇõES FINAIS}

Ao finalizarmos a reflexão diante dos resultados obtidos, voltamos aos objetivos desta investigação: verificar como professores envolvidos em projetos temáticos, nos anos finais do ensino fundamental, percebem o uso das mídias e tecnologias digitais no processo de ensino e de aprendizagem. Podemos considerar que cada professor tem várias possibilidades de organizar sua aula, fugindo da perspectiva do ensino tradicional, no qual o conhecimento é transmitido num processo de recepção pelo aluno.

O mundo atual requer uma visão dinâmica e inovadora no que diz respeito ao processo de ensino e de aprendizagem, principalmente ao utilizar as novas Tecnologias de Informação e Comunicação de forma apropriada e contextualizada. Mas o uso dessas ferramentas tecnológicas sem a formação adequada dos professores, de modo contínuo, não garante mudanças na qualidade das práticas pedagógicas. As novas tecnologias ampliam a prática de sala de aula, sendo fator motivador para o ensino e para a aprendizagem, mas para isso novos posicionamentos devem ser adotados em relação à formação inicial e continuada dos professores, favorecendo sua aproximação do uso das TIC no planejamento e execução de atividades escolares.

Outro aspecto relevante é a importância na manutenção técnica dos computadores e a existência de uma equipe auxiliar (no caso, bolsistas de iniciação científica e/ou estagiários) para o uso das TIC, assegurando equipamentos para todos os alunos, seu funcionamento de modo adequado e uma orientação mais individualizada dos estudantes.

\section{REFERÊNCIAS}

ALVES, A. J. O planejamento da pesquisa qualitativa em educação. Caderno de Pesquisa. São Paulo, n. $71,1991$.

BARDIN, L. Análise de Conteúdo. Lisboa: Edições 70, LDA, 2008. 
Bortoletto-Santos, Colnago e Mascarenhas, 2016 - Tecnologia Educacional

BORTOLETTO-SANTOS, R.C.; COLNAGO, N.A.S.; MASCARENHAS, Y.P. Almanaque Digital: uma proposta para uso das TICs no ensino fundamental. Anais do Cong. Ib.-Am. de C., Tec., In. e Educação, Buenos Aires, Argentina, 2014.

DE CORTE, E. Psychologycal Aspects of Changes in Learning Supported by Informatics. In: Jhonson, D.C.; SAMWAYS, B. (Org.). Informatics and Changes in Learning. North Holland: Elsevier Science Publishers B. V., 1993.

DIEESE. Departamento Intersindical de Estatística e Estudos Socioeconômicos. Transformações recentes no perfil dos docentes das escolas estaduais e municipais da educação básica. Nota Técnica no 141 - out 2014. Disponível em: <http://www.dieese.org.br/notatecnica/2014/notaTec141DocentesPnadvf.pdf>. Acesso em: 15 mar. 2015.

FRANCO, M. L. P. B. Análise de Conteúdo. Brasília: Liber Livro Editora, 2005.

FREIRE, P. Pedagogia do Oprimido. Rio de Janeiro: Paz e Terra, 1981.

. Pedagogia da Esperança. Rio de Janeiro: Paz e Terra, 1994.

Pedagogia da Autonomia. Rio de Janeiro: Paz e Terra, 2000.

GHEDIN E.; FRANCO, M. A. S. Questões de método na construção da pesquisa em educação. São Paulo: Cortez, 2008.

GOMES, N. G. Os computadores chegam à escola: e, agora professor? Anais do IV Seminário de Pesquisa em Educação da Região Sul. Florianópolis, 2002. Disponível em: <portalanpedsul.com.br/admin/uploads/2002/ educacao_e_comunicacao/Mesa_Redonda/12_34_52_m23-145.pdf>. Acesso em: 30 ago.2014.

KENSKI, V. M. Novas tecnologias, o redimensionamento do espaço e do tempo e os impactos no trabalho docente. Informática Educativa, v. 12, n. 1, p. 35-52, 1999.

KENSKI, V.M. Tecnologias e Ensino Presencial e a Distância. Campinas: Papirus, 2008.

JONASSEN, D. H. Computadores, ferramentas cognitivas para desenvolver o pensamento crítico nas escolas. Porto: Porto, 2007.

LAVILLE, C.; DIONNE, J. A construção do saber: manual de metodologia da pesquisa em Ciências Humanas. Porto Alegre: Artmed; Belo Horizonte: Editora UFMG, 1999.

LUDKE, M.; ANDRÉ, M. E. D. A. A pesquisa em educação: abordagem qualitativa. São Paulo: EPU, 1986.

WILSEK, M. A. G.; TOSIN, J. A. P. Ensinar e Aprender Ciências no Ensino Fundamental com Atividades Investigativas através da Resolução de Problemas. Curitiba, 2009. Disponível em: <http://www.diaadiaeducacao.pr.gov.br/portals/pde/arquivos/1686-8.pdf>. Acesso em: 8 mar. 2015.

MORAN, J. M. Como utilizar a Internet na educação. Ciência da Informação, v.26, n.2. Brasília, mai/ago, 1997. et al. Novas tecnologias e mediação pedagógica. Campinas: Papirus, 2000.

PARDO, M. B. L. Princípios de Educação - Planejamento de Ensino. Ribeirão Preto: Culto à Ciência, 1997.

TARDIF, M. Saberes docentes e formação profissional. Petrópolis: Vozes, 2002.

VALENTE, J. A. Informática na Educação: conformar ou transformar a escola. Perspectiva, v.13, n.24, p.41-49. Florianópolis, UFSC/CED, NUP, 1995. 